UDC 32.7

Submitted: 03.02.2016

LBC 66.4(5Япо)

Accepted: 07.03.2016

\title{
INSTITUTIONALISATION OF JAPAN IDENTITY CONSTRUCTION POLICY
}

\author{
Elena S. Zadvornaya
}

Far East Federal University, Vladivostok, Russian Federation

\begin{abstract}
The article is devoted to the development of the modern politics of identity construction in Japan, which actively refers to the practice of designing self-image in international relations. This trend dates back to the 19th century, when there was the end of Sakoku (Japan's policy of isolation). It is now possible to talk about the institutionalization of the identity construction policy to organized structures and regulations. Enhanced efforts in the field of Japanese traditional and popular culture, education and creative content has led to a number of institutions appearance (like Japan Foundation Fund, Japan Creative Agency, Japan Culture Fund, Agency for Cultural Affairs, Cool Japan Fund, Japan brand Fund) and changing idea about the role of culture in foreign policy realization (it is fixed the documents of the Japanese Ministry of Foreign Affairs, the Ministry of Land, Infrastructure, Transport and Tourism, the Ministry of Education, Culture, Sports, Science and Technology, the Ministry of Economy, Trade and Industry), as well as a number of projects (Cool Japan, Visit Japan, Japan Culture Power, Japan Manga Awards, Kawaii Ambassadors, Cosplay International Fest and etc.). These efforts are aimed at forming Japan identity abroad to solve a number of foreign policy challenges of the future and the development of economic cooperation. The Japanese government nearest plans is to increase funding in order to create a positive image of Japan in the region of East Asia. All of these allows us to speak about the policy of the Japanese construction of identity as an institutionalized process in which there was clearance of organizations and regulatory activities.
\end{abstract}

Key words: identity, Japan, foreign policy, identity construction policy, constructivism.

УДК 32.7

Дата поступления статьи: 03.02.2016

ББК 66.4(5Япо)

Дата принятия статьи: 07.03.2016

\section{ИНСТИТУЦИОНАЛИЗАЦИЯ ОБРАЗА ЯПОНИИ В ГОСУДАРСТВЕННОМ ВНЕШНЕПОЛИТИЧЕСКОМ ДИСКУРСЕ}

\section{Елена Сергеевна Задворная}

Дальневосточный федеральный университет, г. Владивосток, Российская Федерация

\begin{abstract}
Аннотация. Статья посвящена развитию современной политики конструирования идентичности Японии, которая активно обращается к практике конструирования собственного образа в межгосударственных отношениях с XIX в., когда произошло окончание политики изоляции. В настоящее время можно говорить об институционализации данного явления - переходе к организованным структурам и официальной регламентации политики конструирования идентичности. Активизация усилий в области японской традиционной и популярной культуры, образования и творческого контента привела к появлению ряда институтов (фондов, агентств, общественных организаций) в сфере формирования образа Японии на международной арене, изменению представлений о роли культуры во внешней политике в документах японских Министерства иностранных дел, Министерства экономики, торговли и промышленности, Министерства транспорта и туризма, а также реализации ряда проектов, направленных на формирование представлений о современной Японии за рубежом, для решения ряда внешнеполитических задач в будущем и развития экономического сотрудничества.
\end{abstract}

Ключевые слова: идентичность, Япония, внешняя политика, политика конструирования идентичности, конструктивизм.

Понятие «идентичность» активно употребляется в различных областях современно- го научного знания. При всех значениях сохраняется представление о том, что речь идет о 
человеке или группе, выделенных в процессах различений/отождествлений. Конец 1960-х начало 1970-х гг. являются рубежом в развитии концепции идентичности, когда из абстрактной категории идентичность превращается в одно из ключевых понятий общественных наук. Процессам персональной и групповой идентификации были посвящены многие исследования в области психологии, социологии и антропологии, а в конце XX в. данные наработки были восприняты политологами и исследователями международных отношений (школа политического конструктивизма). Принципиальным является момент об искусственном характере идентичности и ее политической природе, так как именно политические факторы ее формирования и специфика развития в решении политических задач выводятся на первый план исследований.

Япония имеет длительный опыт формирования собственного образа - с момента открытия государства в 1853 г. были использованы разнообразные методы, связанные с развитием представлений о загадочной стране и уникальной культуре (в XIX в.), сильной и могущественной империи (в первой половине XX в.), миролюбивом государстве, занятом восстановлением экономики (после окончания Второй мировой войны). Тем не менее до середины XX в. вряд ли можно говорить о целенаправленной политике конструирования идентичности Японии, как как имели место лишь отголоски прежней политики самоизоляции, которая превратила страну в непривычный для западного восприятия феномен. Далее, вплоть до окончания Второй мировой войны, на процессы формирования образа Японии оказала серьезное влияние политика расового превосходства японской нации. И только начиная с 1960-х гг. благодаря активной интеграции страны Восходящего солнца в мировое сообщество и науку осмысление оригинальных образов становится содержанием государственной политики.

В 1980-е гг. Япония вступает в новый этап конструирования своей идентичности на международной арене. Одна из причин изменения данной политики связана с развитием экономического сотрудничества в Восточной Азии. История свидетельствует о небывалом экономическом росте Японии с 1950-х по конец 1970-х гг., однако в связи с финансовыми спекуляциями в конце 1980-х происходит падение на рынке недвижимости, вызвавшее неплатежи по кредитам и банкротства. Данный экономический кризис переориентировал японские корпорации начать экономическую экспансию в страны Восточной Азии в связи с более высоким процентом прибыли на развивающихся рынках в области кредитования, инвестиций и строительства. В этот период японская политика была направлена на создание позитивной атмосферы для развития экономического сотрудничества. Ключевым становится образ Японии как страны высоких технологий и эффективного менеджмента.

Однако в 1970-1980 гг. Япония активизирует усилия в области формирования нового образа страны, что во многом было связано с расширением связей КНР на международной арене. В этот же период Китай проводит политику модернизации и открытости, а в 1972 г. устанавливает дипломатические отношения с Японией. В связи с этим в 1972 г. в Голубой дипломатической книге Японии впервые упоминается, что для развития отношений с другими странами необходимо формирование атмосферы взаимопонимания и развитие культурных обменов [21]. В 1973 г. уже утверждается, что если ранее дипломатия Японии делала ставку на экономические и политические методы, то сейчас следует уделять внимание методам культурной дипломатии [22]. Для реализации данного направления было предложено создание Японского фонда, который будет осуществлять продвижение японской культуры в других странах на систематической, плановой основе с государственным участием. Основными задачами стали формирование образа Японии как полноправного участника международных отношений, конкуренция с КНР в области формирования представления о лидере в регионе Восточная Азия, а в качестве основного метода была избрана популяризация современной молодежной культуры Японии за рубежом.

Создание Японского фонда международных культурных обменов (в 1972 г.) как организации, подчиненной Министерству иностранных дел, является важным событием в институционализации японской политики конструирования идентичности, так как главными це- 
лями работы Фонда являются популяризация японской культуры и формирование позитивного образа Японии за рубежом. Для этого разработаны различные программы и направления деятельности: обмены в области культуры и искусства, преподавание японского языка за рубежом, программы поддержки исследований Японии и интеллектуальных обменов.

Достаточно серьезное внимание уделяется популяризации японского языка за рубежом. Деятельность Японского фонда в рамках данного направления сосредоточена на финансовой и кадровой поддержке институтов японского языка за рубежом, разработке учебных программ, предоставлении учебных материалов, организации стажировок и повышении квалификации для иностранных преподавателей японского языка. Кроме того, Фонд совместно с Японской службой образования и культурных обменов в 1984 г. создал систему тестирования и определения уровня японского языка [14]. Деятельность Фонда по популяризации японского языка можно оценить как вполне успешную, так как количество человек, вовлеченных в обучение японскому языку, выросло в мире на 25,4 \% с 2006 по 2012 г. (до 3,98 млн человек) [25]. Фонд имеет представительства в 21 стране мира: Япония, Австралия, Индонезия, Малайзия, Филиппины, Вьетнам, Таиланд, КНР, Индия, Россия, Венгрия, Италия, Франция, Испания, Великобритания, Германия, Египет, США, Канада, Мексика, Бразилия [13].

Дальнейшая активизация КНР на международной арене рассматривается как важнейшее внешнеполитическое событие 1979 г. в Голубой дипломатической книге Японии (происходит установление дипломатических отношений с США, поездка министра иностранных дел КНР в Европу) [18]. Это значительным образом повлияло на постановку долгосрочных целей внешней политики Японии, когда в 1980 г. было обозначено продвижение нового представления о стране Восходящего солнца, для чего необходимо осуществлять культурные, научные обмены и привлекать иностранных студентов в японские учебные заведения. В целях реализации данного тезиса в 1980 г. Япония подписала 28 договоров о культурных обменах, а также стартовал ряд программ в области культурной дипломатии [12].
Ранее, в 1968 г., было организовано государственное Агентство по культуре как подразделение Министерства культуры и образования Японии. Его основной задачей в настоящее время является разработка и внедрение разнообразных направлений деятельности с целью популяризации японской культуры и языка в мире для увеличения воздействия «японской силы культуры». В 2010 г. бюджет Министерства составил 10,2\% от национального бюджета Японии, а доля Агентства по культуре $-1,8 \%$ от бюджета Министерства [17].

Важной инициативой Агентства стало формирование базы национального культурного достояния в сфере современной японской культуры. Сбор информации происходит по категориям манга, анимация, видеоигры и медиаискусство. Кроме этого Агентство запустило инициативу по формированию представления о новой японской нации к 2020 г., мощь которой заключается в силе культуры [8].

В 2004 г. в рамках японского Министерства иностранных дел был создан Департамент публичной дипломатии. С этого времени начинают использоваться темы молодежной субкультуры в государственном внешнеполитическом дискурсе, которые формируют яркий образ Японии при помощи современной музыки, моды и графической культуры. Как следствие, в качестве отдельного направления выделяется культурная дипломатия и в Голубой книге 2005 года. Там же упоминается термин «мягкая сила», которую следует рассматривать как следствие ряда внешнеполитических действий, в результате которых формируются чувства благодарности, восхищения Японией и конструируется необходимый образ государства [11]. В качестве методов указываются международные обмены в области культуры, образования и спорта: студенческие, научные, культурные обмены и стажировки, продвижение японского языка за рубежом, инициирование японских исследований, работа в ЮНЕСКО по регистрации объектов культурного наследия и помощь развивающимся странам в сохранении их объектов культуры. Также важным методом является развитие связей с зарубежной общественностью и привлечение иностранных туристов в Японию, которые понимаются как деятельность по формированию определенного обра- 
за Японии [4]. При этом подчеркивается важность расширения знаний о японских реалиях, которые помогают понимать происходящее с японской точки зрения.

Также в 2004 г. в качестве самостоятельного направления внешнеполитической деятельности Японии выделяется «поп-дипломатия» (Pop-diplomacy) [20]. Цель данного направления - объяснять и корректировать информацию о Японии, а также влиять на формирование положительного образа путем обращения к популярной культуре. Для этого МИД Японии учреждает в 2007 г. международную премию манга, с 2008 г. появляются аниме-послы и аниме-представители Японии, в 2011 г. учреждается Международный саммит-косплей с призами от МИД Японии, осуществляется поддержка Japan EXPO (крупнейшая выставка для знакомства с популярной японской культурой - манга, аниме, видеоигры, музыка и мода).

Кроме того, начиная с 1960-х гг. японское правительство предпринимает серьезные усилия по конструированию образа гостеприимной, безопасной и интересной Японии. В 1963 г. был принят закон, регулирующий отношения в области туризма в Японии. Следом, в 1964 г., была создана Национальная туристическая организация Японии, целью которой являются межкультурные обмены путем развития туризма. К основным методам работы организации относятся распространение видео- и печатных материалов о туристическом потенциале Японии, проведение исследований ожиданий иностранных респондентов, туристических выставок и ярмарок, предоставление туристической информации, координация работы представительств за рубежом. Региональные офисы открыты в 11 странах мира, из них 3 в КНР и 1 в Республике Корея. Также существует ряд программ по привлечению иностранных туристов, но самой популярной является «Посетите Японию» (Visit Japan), которая создана Министерством транспорта и туризма Японии в 2003 году [15]. Анонсируя данную программу, Министерство указало достижение показателя 10 млн иностранных туристов в год (к 2010 г.) в качестве одной из основных задач. Данный уровень был зафиксирован только в 2013 году [16]. В 2015 г. зафиксирован небывалый рост посещений
Японии иностранными туристами - в целом на $47 \%$ [1]. При этом на $109 \%$ вырос поток из КНР (4,6 млн человек за 2015 г.), на $66 \%$ из Гонконга (1,4 млн человек), на $30 \%$ из Тайваня (3,4 млн человек), на 44 \% из Республики Корея (3,6 млн человек). Соответственно следует сделать вывод об эффективности данной программы и достижении поставленных целей в формировании положительного образа Японии, несмотря на землетрясение и аварию на АЭС Фукусима в 2011 году.

Важным методом формирования образа Японии за рубежом является проект «Cool Јарап» (Крутая Япония), целью которого является популяризация японской творческой индустрии. В настоящее время за реализацию данного проекта отвечает Департамент творческой индустрии Японии (подразделение Бюро коммерческой и информационной политики в Министерстве экономики, торговли и промышленности Японии). Учреждение в 2013 г. Фонда «Cool Japan» служит целям продвижения японских творческих продуктов за рубежом (в качестве основных категорий выделяют национальную кухню, предметы быта, моду, творческий контент и искусство). Акцент в создании фонда делается на оптимизации получения и распределения финансовых потоков на необходимые мероприятия. При этом вклад правительства Японии на 2013 г. составлял 30 млрд иен [23]. Следует отметить специфику формирования образа Японии в каждой из стран Северо-Восточной Азии. Так, в рамках проекта «Cool Japan» в КНР ставка делается на продажу японских медийных продуктов при помощи китайского телевидения и интернет-коммерции, продажи бытовых и строительных товаров и пр. В Южной Корее акцент делается на продажу японских продуктов питания, а также продвижение туризма, а также поддержку японской уличной моды [2].

В 2013 г. Министерством экономики, торговли и промышленности был основан Международный комитет по творческой индустрии для поддержки и продвижения японской культуры и контента за рубежом. Членами комитета были избраны ведущие специалисты в области современной культуры: Унозава Син - президент корпорации видеоигр «Bandai Namco Games», Китагава Наоки - президент 
«Sony Music Entertainment», Нома Ёсинобу президент издательства «Kodansha», Хори Ёситака - президент продюсерского центра «HoriPro» и Дэнни Чу - продюсер проекта «Culture Japan» [6].

Согласно отчету Комитета по творческой индустрии Японии за 2014 г. в будущем планируется формировать «японский бум». Для этого следует развивать зарубежные возможности в формировании «привлекательной Японии», контролируя качество и наполнение информацией этих каналов, то есть фокусироваться на привлекательных чертах в целом, а не на отдельных продуктах и услугах (например, японской кухне, а не суши). Предполагается увеличение поставок японского контента за рубеж за счет таких мер, как расширение «связанного контента» - например, добавление субтитров на японском языке или контроль использования авторских прав. Поддержка и продвижение японского контента за рубежом будут осуществляться при помощи Департамента продвижения японского контента [10], а также во взаимодействии с зарубежными офисами JETRO, Национальной туристической организации Японии, активном содействии со стороны Каннского международного кинофестиваля и Japan EXPO.

Следующее направление - управление образом Японии в среде зарубежных фангрупп и блогеров. Планируется задействовать программу «CoFesta Ambassador» [9] (посланники фестиваля японского контента), куда активно вовлекаются иностранные студенты, а также «Contents Portal Site» (JAPACON) [25] портал, продвигающий японский контент, и «Asia Trend Мар» [3] (Карта предпочтений стран Азии) - сайт, созданный при поддержке Министерства экономики Японии, предоставляющий информацию об уровне популярности в разных странах различных японских компьютерных игр, аниме или манга.

Следующим направлением является формирование образа высокодоходного прибыльного бизнеса при использовании японского контента. Для этого планируется создание сети дистрибуции, в которую будут вовлечены как японский малый бизнес, так и крупные корпорации, а также иностранные компании и агенты. Согласно планам Министерства экономи- ки, торговли и промышленности к 2020 г. Япония собирается завоевать $10 \%$ сегмента мирового рынка творческой индустрии, а максимальный рост японского влияния планируется в КНР и Индии - $12 \%$ [7].

Создание Фонда «Японский бренд» в 2013 г. с бюджетом 50 млрд иен [5] является следующим направлением, в рамках которого будет возможно оперативно реагировать на какие-либо изменения. Приоритетными признаются направления, которые смогут охватывать самую широкую аудиторию и сформировать лояльность по отношению к «эксклюзивно японскому».

Следующим пунктом является побуждение иностранцев посетить Японию, где они смогут получить новое позитивное представление об этой стране. Для этого следует использовать методы событийного маркетинга: выставки, шоу, фестивали, ярмарки. Кроме того, необходимо обращаться к темам, связанным с творческим контентом, таким как Токийский международный кинофестиваль, Tokyo Game Show, проект «Creative Tokyo», в котором реализуется образ Японии как международного центра современного дизайна, для чего ежегодно организуются мероприятия в рамках «Пяти недель творчества», «Международного форума творчества» и «Осеннего Токио».

Планы развития проекта «Cool Japan» за рубежом являются важным направлением деятельности. Предполагается строительство торговых центров, в которых будут представлены японские бренды, получение прав на телевещание на основных национальных каналах и представление японской продукции, кухни и стиля, организация так называемых японских food-court (этажи ресторанчиков в торговых и развлекательных комплексах), помощь частному бизнесу в развитии продаж японских товаров и услуг (отделочные материалы, мебель, косметика), а также государственная поддержка в виде налоговых льгот, найма персонала и различных консультаций. В рамках проекта «Cool Japan» в 2015 г. была запущена инициатива «Nippon quest» (Загадки Японии) [19] - портал, который предлагает получить информацию о различных уникальных особенностях Японии, организацию медиатуров для влиятельных журналистов и предста- 
вителей зарубежных СМИ по живописным и памятным местам Японии, проведение недели национальных промыслов, что отражает поворот в сторону популяризации традиционной культуры Японии.

Таким образом, новые международные вызовы конца XX в. и экономическая стагнация конца 1980-х гг. заставили Японию пересмотреть свою политику конструирования идентичности: происходит обращение к популярной культуре, увеличение государственных институтов и общественных организаций, вовлеченных в данную деятельность, и экспорт продуктов творческой индустрии в страны Восточной Азии. Новая волна связана с процессами развития регионализма и противоборством с усилиями КНР стать лидером в регионе. Японское правительство пытается изменить негативные представления о Японии среди молодых китайцев и корейцев, что скоpeе составляет долгосрочную стратегию решения ряда политических и экономических вопросов в будущем, нежели преследует ближайшие цели.

Современная политика конструирования японской идентичности за рубежом является важным направлением деятельности всей системы государственных органов Японии. Сформирована система государственных институтов и агентств, ответственных за реализацию данного направления. В ближайших планах японского правительства расширение финансирования с целью формирования позитивного образа Японии в регионе Восточная Азия. Все это позволяет говорить о политике конструирования японской идентичности как институционализированном процессе, в рамках которого произошло оформление системы организаций и регламентация направлений деятельности.

В заключение следует отметить то, что межэтнические и межнациональные отношения являются предметом регулирования и управления со стороны японского правительства - были созданы разнообразные институты, сформулированы направления развития. При этом существует политика сохранения уникальной японской самоидентификации. Однако в силу экономической стагнации в Японии, а также более активных действий в данной области таких соседей, как КНР и
Республика Корея, вышеперечисленные меры представляются не вполне достаточными с точки зрения результативности по формированию образа Японии в регионе Восточная Азия.

\section{СПИСОК ЛИТЕРАТУРЫ}

1. 2015 - Statistics for foreign visitors and Japanese departures // Japan National Tourism Organization. - Electronic text data. - Mode of access: https://www.jnto.go.jp/eng/ttp/sta/. - Title from screen.

2. An Interim report compiled by the Creative industries internationalization committee. 21.06.2013 // Ministry of economy, trade and industry of Japan. Electronic text data. - Mode of access: http:// www.meti.go.jp/english/press/2013/0621_01.html(date of access: 22.11.2014). - Title from screen.

3. Asia Trend Map - about. - Electronic text data. - Mode of access: http://www.asiatrendmap.jp/en (date of access: 03.03.2015). - Title from screen.

4. Building multilateral diplomatic foundation. Japan Diplomatic Bluebook. 2005 // Ministry of foreign affairs of Japan. - Electronic text data. - Mode of access: http://www.mofa.go.jp/policy/other/bluebook/2005/ ch5.pdf(date of access: 21.10.2015). - Title from screen.

5. Cabinet decision on the bill of the Act on establishment of the Japan Brand Fund. 15.03.2013 // Ministry of economy, trade and industry of Japan. Electronic text data. - Mode of access: http:// www.meti.go.jp/english/press/2013/0315_04.html (date of access: 25.10.2015). - Title from screen.

6. Danny Choo. Creative industry institutionalizing committee. - Electronic text data. - Mode of access: http://www.dannychoo.com/en/post/26903/Creative+ Industries+Internationalization+Committee.html (date of access: 15.11.2015). - Title from screen.

7. Global entertainment and media review (20152016 years) // PWC Publishing Group. 2014. - Electronic text data. - Mode of access: http://www.pwc.com/gx/ en/industries/entertainment-media/outlook.html (date of access: 16.10.2015). - Title from screen.

8. Intermediary plan towards creating a nation based on culture and the arts // Ministry of education, culture, sports, science and technology of Japan. Electronic text data. - Mode of access: http:// www.mext.go.jp/english/topics/_icsFiles/afieldfile/2014/ 04/23/1347213_1_1.pdf(date of access: 17.03.2015).Title from screen.

9. Interviews with "CoFesta Ambassadors". Vol. 1 (01.04.2014). - Electronic text data. - Mode of access: http://jcs2014.com/en/release/newsletter/ detail8.html (date of access: 24.04.2015). - Title from screen.

10. Japan content expansion department functions. 2013 // Ministry of economy, trade and industry of 
Japan. - Electronic text data. - Mode of access: http:// www.meti.go.jp/english/press/2013/pdf/0621_01a.pdf (date of access: 07.03.2015). - Title from screen.

11. Japan Diplomatic Bluebook. 2005 // Ministry of foreign affairs of Japan. - Electronic text data. Mode of access: http://www.mofa.go.jp/policy/other/ bluebook/2005/ch3-e.pdf(date of access: 10.11.2015). Title from screen.

12. Japan Diplomatic Bluebook. 1980 // Ministry of foreign affairs of Japan. - Electronic text data. Mode of access: http://www.mofa.go.jp/policy/other/ bluebook/1981/1981-3-5.htm (date of access: 16.11.2015). - Title from screen.

13. Japan Fund regional offices. - Electronic text data. - Mode of access: http://www.jpf.go.jp/world/ en/index.html (date of access: 10.02.2015). - Title from screen.

14. Japan language proficiency test. - Electronic text data. - Mode of access: http://www.jlpt.jp/e/ index.html (date of access: 27.06.2015). - Title from screen.

15. Japan Ministry of land, infrastructure and tourism report on 2003: Making Japan a tourism-based country // Ministry of land, infrastructure, transport and tourism of Japan. - Electronic text data. - Mode of access: http://www.mlit.go.jp/english/white-paper/ mlit03/p2c2.pdf(date of access: 19.05.2015). - Title from screen.

16. Japan Ministry of land, infrastructure and tourism report on 2013: Realizing a tourism nation and beautiful nation building // Ministry of land, infrastructure, transport and tourism of Japan. Electronic text data. - Mode of access: http:// www.mlit.go.jp/common/001063083.pdf(date of access: 24.05.2015). - Title from screen.

17. Japan national budget for FY 2010. Electronic text data. - Mode of access: http:// www.mext.go.jp/english/budget/index.htm (date of access: 19.12.2014). - Title from screen.

18. Major international development in 1979. Diplomatic Bluebook. 1980 // Ministry of foreign affairs of Japan. - Electronic text data. - Mode of access: http://www.mofa.go.jp/policy/other/bluebook/1980/ 1980-1.htm (date of access: 26.05.2015). - Title from screen.

19. Nippon quest. - Electronic text data. - Mode of access: https://nipponquest.com (date of access: 08.06.2015). - Title from screen.

20. Pop-culture diplomacy of Japan // Ministry of foreign affairs of Japan. - Electronic text data. Mode of access: http://www.mofa.go.jp/policy/culture/ exchange/pop/ (date of access: 29.05.2015). - Title from screen.

21. Promotion of International mutual understanding and cultural exchange. Japan Diplomatic Bluebook. 1971 // Ministry of foreign affairs of Japan. - Electronic text data. - Mode of access: http://www.mofa.go.jp/ policy/other/bluebook/1971/1971-2-6.htm. - Title from screen.

22. Promotion of International mutual understanding and cultural exchange. Japan Diplomatic Bluebook 1972 // Ministry of foreign affairs of Japan. - Electronic text data. - Mode of access: http://www.mofa.go.jp/ policy/other/bluebook/1972/1972-2-7.htm (date of access: 09.04 .2015$)$. - Title from screen.

23. Scheme of the Cool Japan Fund. 2013 // Ministry of economy, trade and industry of Japan. Electronic text data. - Mode of access: http:// www.meti.go.jp/english/policy/mono_info_service/ creative_industries/pdf/20131010_01a.pdf (date of access: 22.04 .2015 ). - Title from screen.

24. Survey report on Japanese-language education abroad. 2012. - Electronic text data. - Mode of access: http://www.jpf.go.jp/e/japanese/survey/ result/index.html (date of access: 16.05.2015). - Title from screen.

25. What is JAPACON? - Electronic text data. Mode of access: http://www.japancontent.jp/static/en/ screen/welcome_jpc/ (date of access: 23.05.2015). Title from screen.

\section{REFERENCES}

1. 2015 - Statistics for Foreign Visitors and Japanese Departures. Japan National Tourism Organization. Available at: https://www.jnto.go.jp/ eng/ttp/sta/.

2. An Interim Report Compiled by the Creative Industries Internationalization Committee. 21.06.2013. Ministry of Economy, Trade and Industry of Japan. Available at: http://www.meti.go.jp/english/press/ 2013/0621_01.html. (accessed November 22, 2014).

3. Asia Trend Map-About. Available at: http:// www.asiatrendmap.jp/en. (accessed March 3, 2015).

4. Building Multilateral Diplomatic Foundation. Japan Diplomatic Bluebook. 2005. Ministry of Foreign Affairs of Japan. Available at: http://www.mofa.go.jp/ policy/other/bluebook/2005/ch5.pdf. (accessed October 21, 2015).

5. Cabinet Decision on the Bill of the Act on Establishment of the Japan Brand Fund. 15.03.2013. Ministry of Economy, Trade and Industry of Japan. Available at: http://www.meti.go.jp/english/press/2013/ 0315_04.html. (accessed October 25, 2015).

6. Danny Choo. Creative Industry institutionalizing Committee. Available at: http:// www.dannychoo.com/en/post/26903/Creative+ Industries+Internationalization+Committee.html. (accessed November 15, 2015).

7. Global Entertainment and Media Review (20152016). PWC Publishing Group. 2014. Available at: 
http://www.pwc.com/gx/en/industries/entertainmentmedia/outlook.html. (accessed October 16, 2015).

8. Intermediary Plan Towards Creating a Nation Based on Culture and the Arts. Ministry of Education, Culture, Sports, Science and Technology of Japan. Available at: http://www.mext.go.jp/english/topics/ icsFiles/afieldfile/2014/04/23/1347213_1_1.pdf (accessed March 17, 2015).

9. Interviews With "CoFesta Ambassadors", 2014, vol. 1, April 1. Available at: http://jcs2014.com/en/ release/newsletter/detail8.html. (accessed April 24, 2015).

10. Japan Content Expansion Department Functions.2013. Ministry of Economy, Trade and Industry of Japan. Available at: http://www.meti.go.jp/ english/press/2013/pdf/0621_01a.pdf. (accessed March 7, 2015).

11. Japan Diplomatic Bluebook. 2005. Ministry of Foreign Affairs of Japan. Available at: http:// www.mofa.go.jp/policy/other/bluebook/2005/ch3e.pdf. (accessed November 10, 2015).

12. Japan Diplomatic Bluebook. 1980. Ministry of Foreign Affairs of Japan. Available at: http:// www.mofa.go.jp/policy/other/bluebook/1981/1981-35.htm. (accessed November 16, 2015).

13. Japan Fund Regional Offices. Available at: http://www.jpf.go.jp/world/en/index.html. (accessed February 10, 2015).

14. Japan Language Proficiency Test. Available at: http://www.jlpt.jp/e/index.html. (accessed June 27, 2015).

15. Japan Ministry of Land, Infrastructure and Tourism Report on 2003: Making Japan a TourismBased Country. Ministry of Land, Infrastructure, Transport and Tourism of Japan. Available at: http:// www.mlit.go.jp/english/white-paper/mlit03/p2c2.pdf. (accessed May 19, 2015).

16. Japan Ministry of Land, Infrastructure and Tourism Report on 2013: Realizing a Tourism Nation and Beautiful Nation Building. Ministry of Land, Infrastructure, Transport and Tourism of Japan.
Available at: http://www.mlit.go.jp/common/ 001063083.pdf. (accessed May 24, 2015).

17. Japan National Budget for FY 2010. Available at: http://www.mext.go.jp/english/budget/ index.htm. (accessed December 19, 2014).

18. Major International Development in 1979. Diplomatic Bluebook. 1980. Ministry of Foreign Affairs of Japan. Available at: http://www.mofa.go.jp/ policy/other/bluebook/1980/1980-1.htm. (accessed May 26, 2015).

19. Nippon Quest. Available at: https:// nipponquest.com (accessed June 8, 2015).

20. Pop-Culture Diplomacy of Japan. Ministry of Foreign Affairs of Japan. Available at: http:// www.mofa.go.jp/policy/culture/exchange/pop/ (accessed May 29, 2015).

21. Promotion of International Mutual Understanding and Cultural Exchange. Japan Diplomatic Bluebook. 1971. Ministry of Foreign Affairs of Japan. Available at: http://www.mofa.go.jp/policy/ other/bluebook/1971/1971-2-6.htm.

22. Promotion of International Mutual Understanding and Cultural Exchange. Japan Diplomatic Bluebook 1972. Ministry of Foreign Affairs of Japan. Available at: http://www.mofa. go.jp/policy/other/bluebook/1972/1972-2-7.htm. (accessed April 9, 2015).

23. Scheme of the Cool Japan Fund. 2013. Ministry of Economy, Trade and Industry of Japan. Available at: http://www.meti.go.jp/english/policy/ mono_info_service/creative_industries/pdf/ 20131010_01a.pdf. (accessed April 22, 2015).

24. Survey Report on Japanese-Language Education Abroad. 2012. Available at: http:// www.jpf.go.jp/e/japanese/survey/result/index.html. (accessed May 16, 2015).

25. What Is JAPACON? Available at: http:// www.japancontent.jp/static/en/screen/welcome_jpc/. (accessed May 23, 2015).

\section{Information About the Author}

Elena S. Zadvornaya, Postgraduate Student, Department of China Studies, School of Regional and International Studies, Far Eastern Federal University (FEFU), Ayaks-10 Village, FEFU Campus, 690000 Vladivostok, Russian Federation, zadvornaya@mail.ru.

\section{Информация об авторе}

Елена Сергеевна Задворная, аспирант кафедры китаеведения, Школа региональных и международных исследований, Дальневосточный федеральный университет, пос. Аякс-10, кампус ДВФУ, 690000 г. Владивосток, Российская Федерация, zadvornaya@mail.ru. 